\title{
Atrás da Porta
}

segundo lead sheet editada por Almir Chediak*

e gravação de Elis Regina no video Na Batucada da Vida (1973) ***
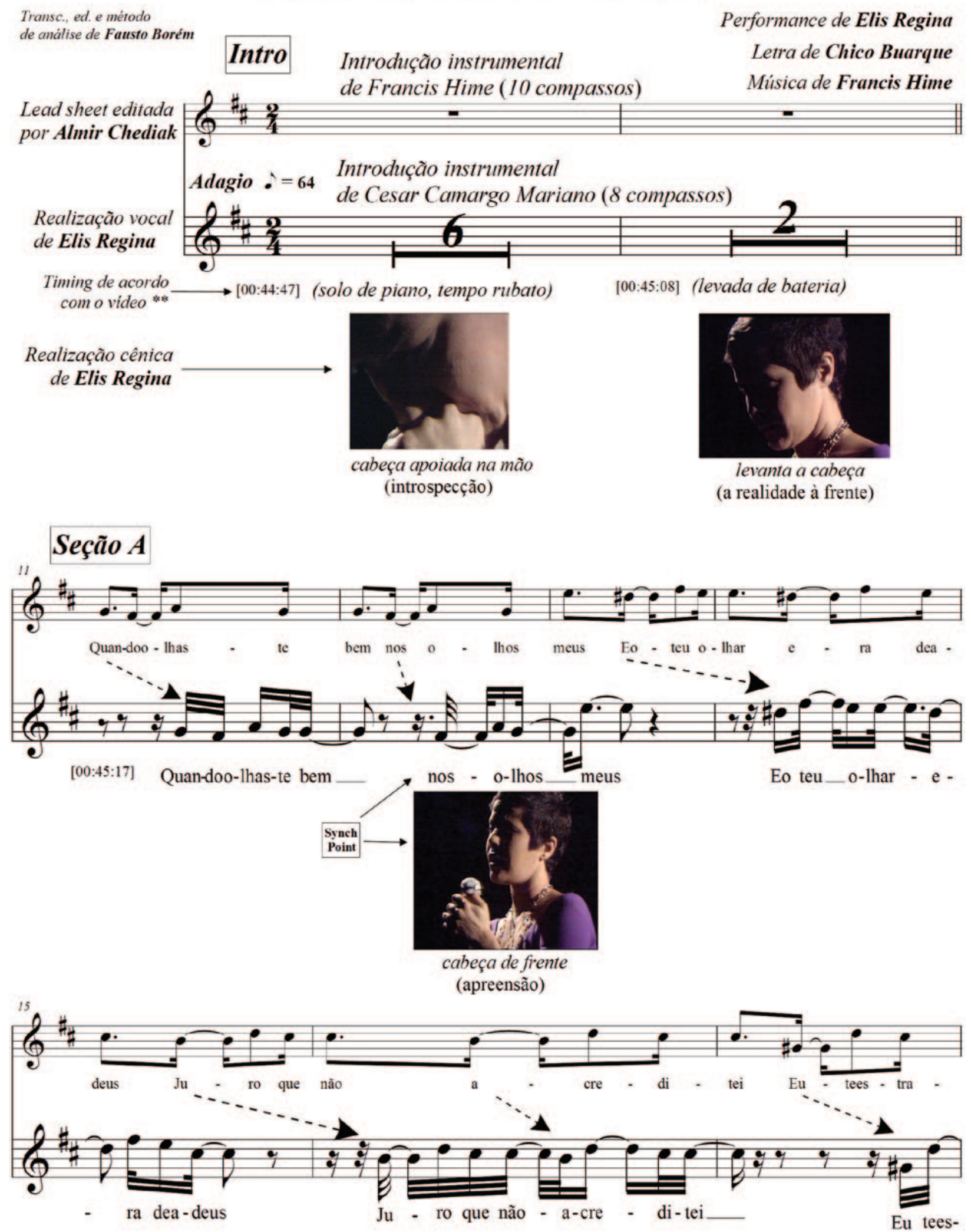


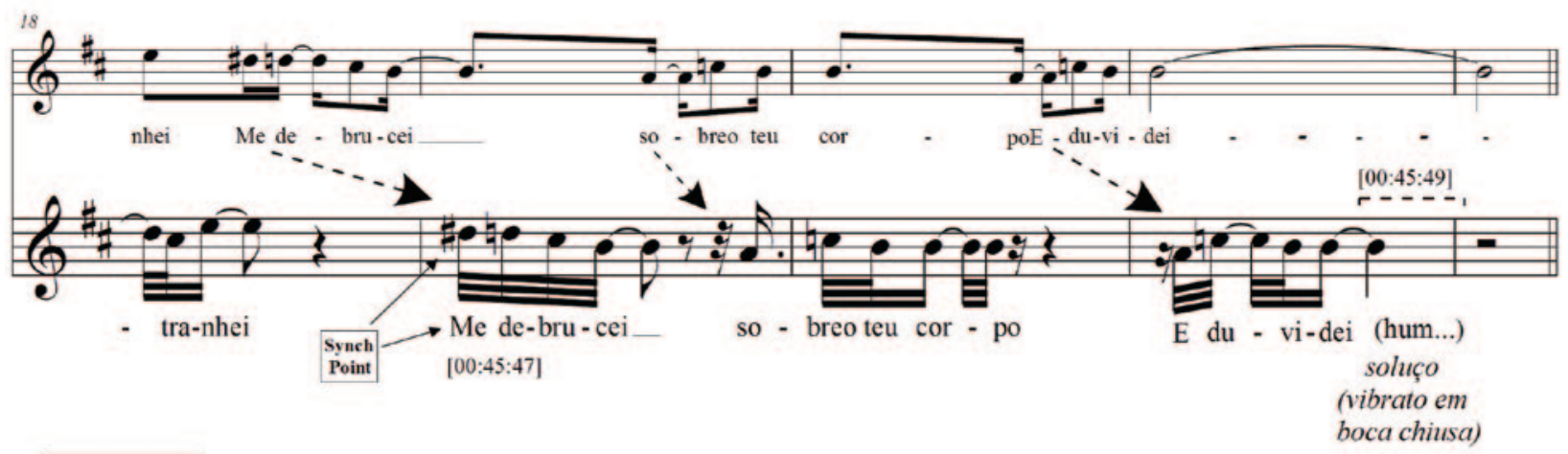

\section{Seção B 1}
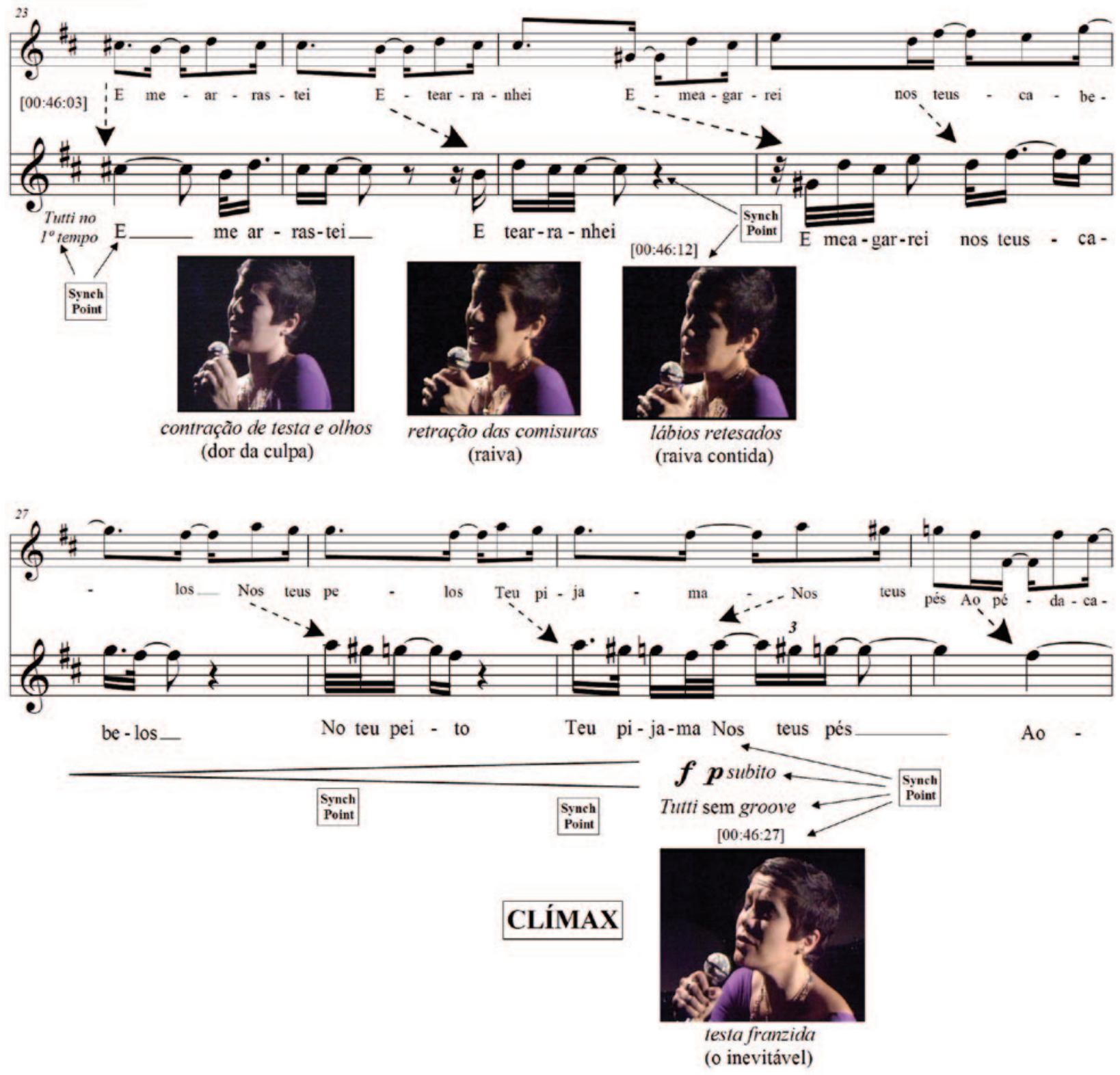

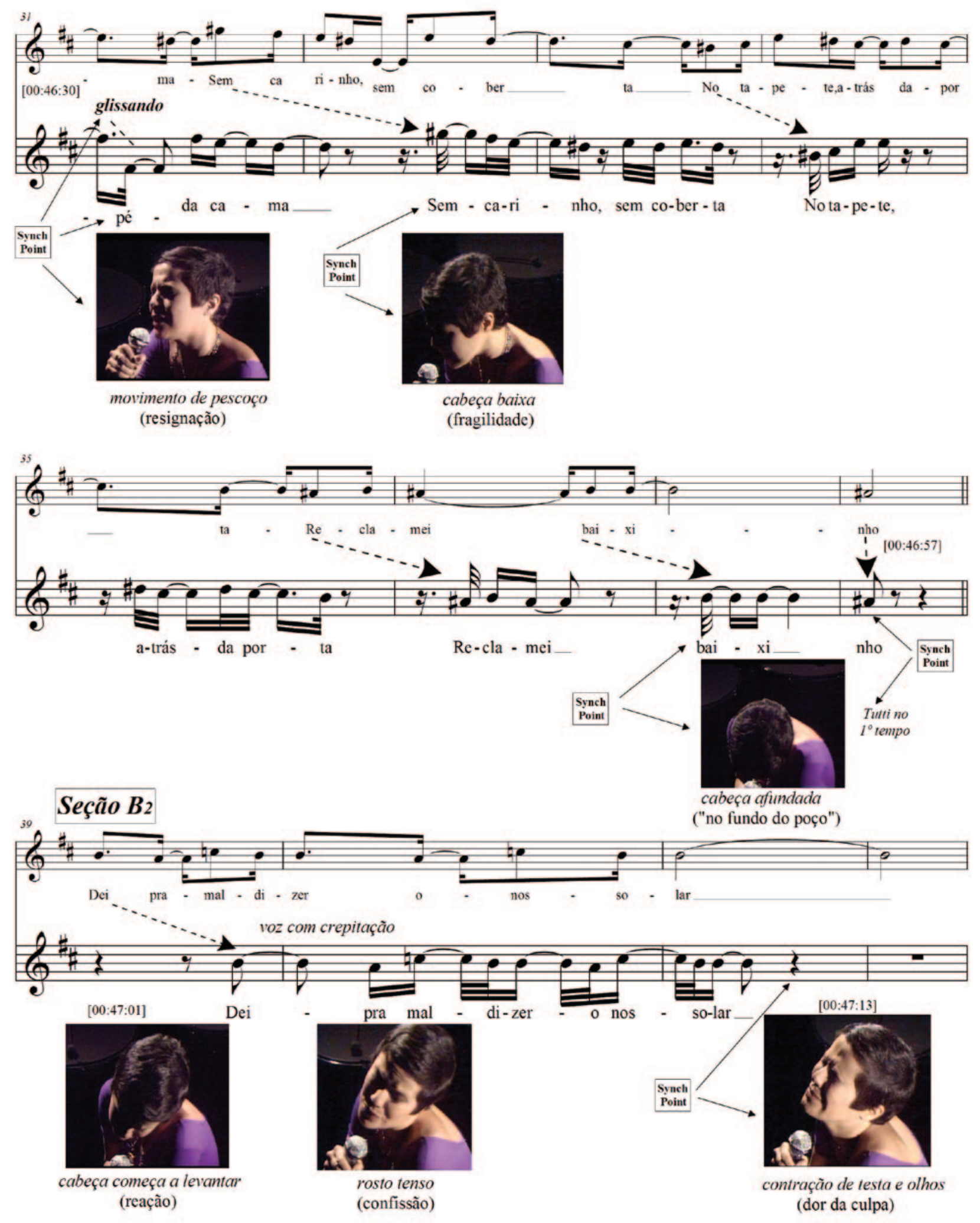

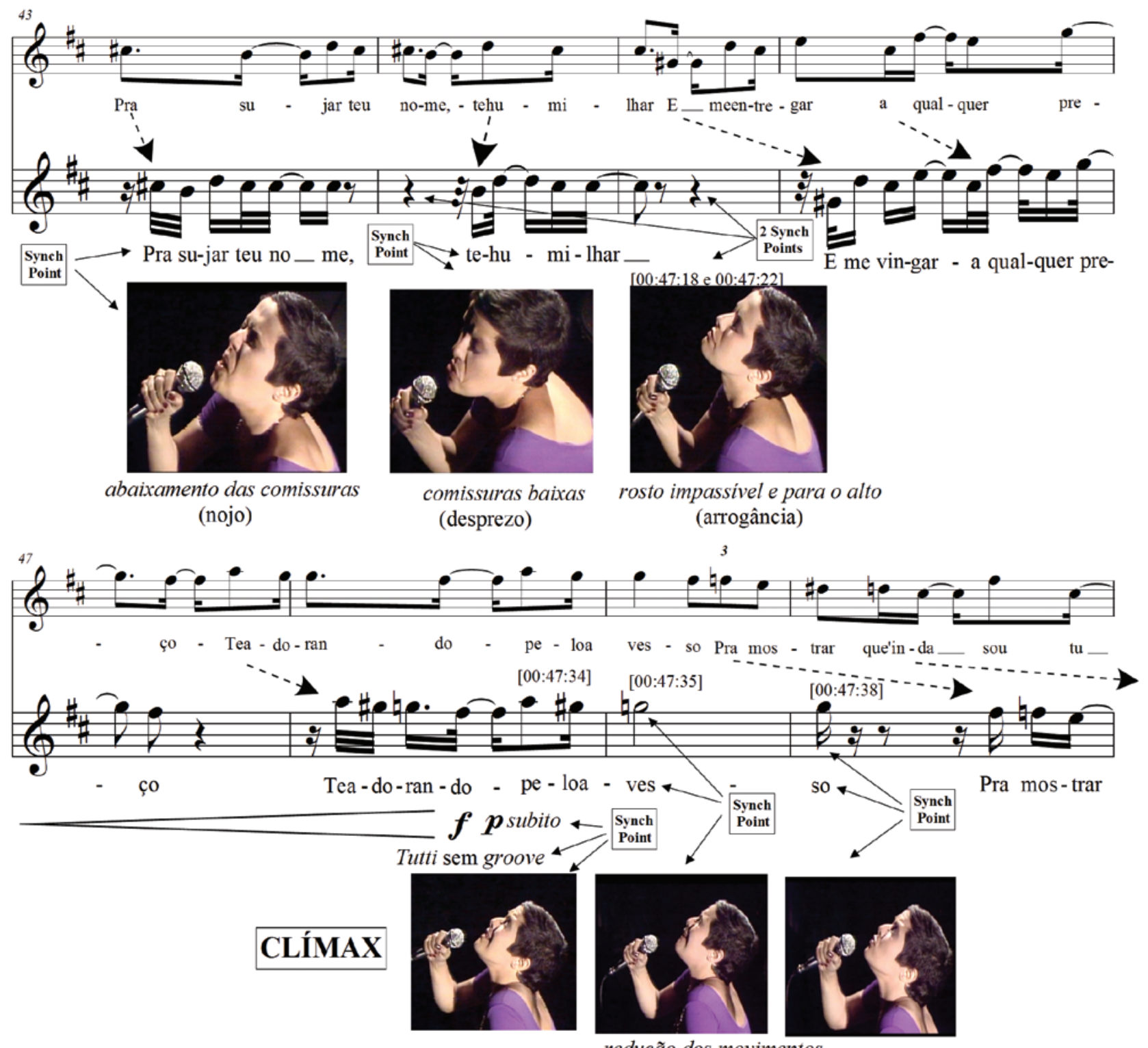

Coda (reconhecimento)
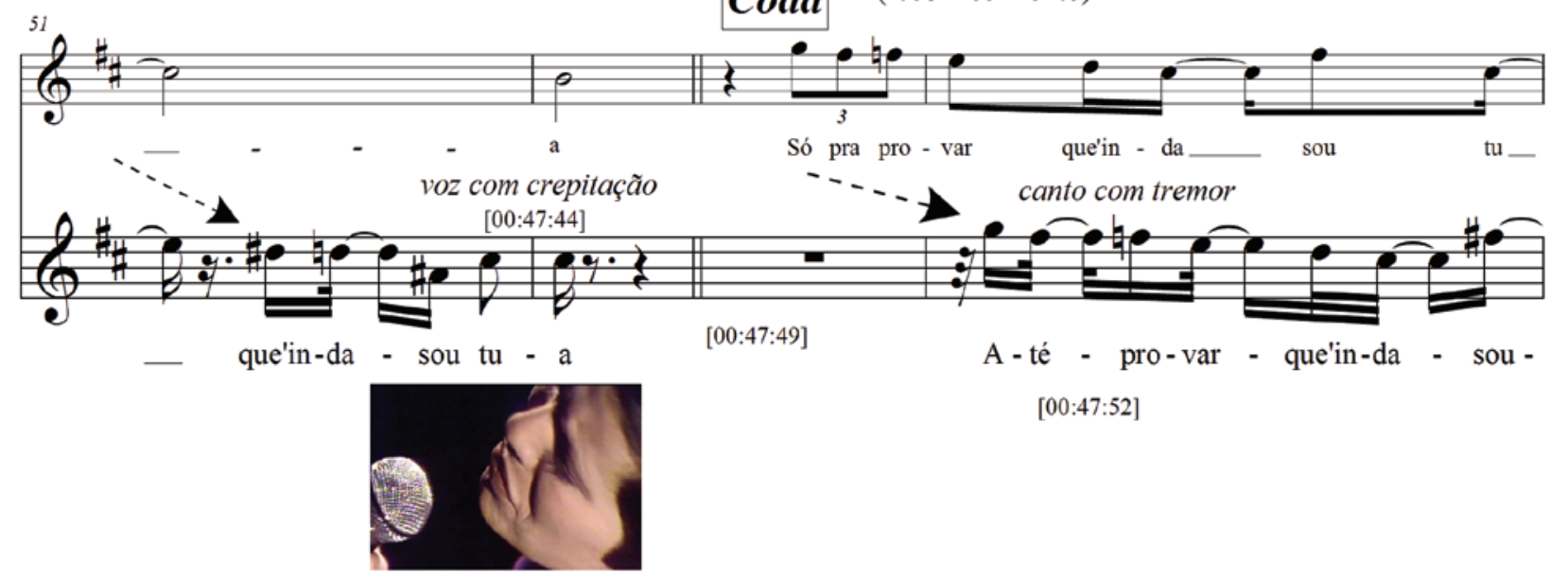

$[00: 47: 52]$

cabeça pendente

(volta à submissão) 


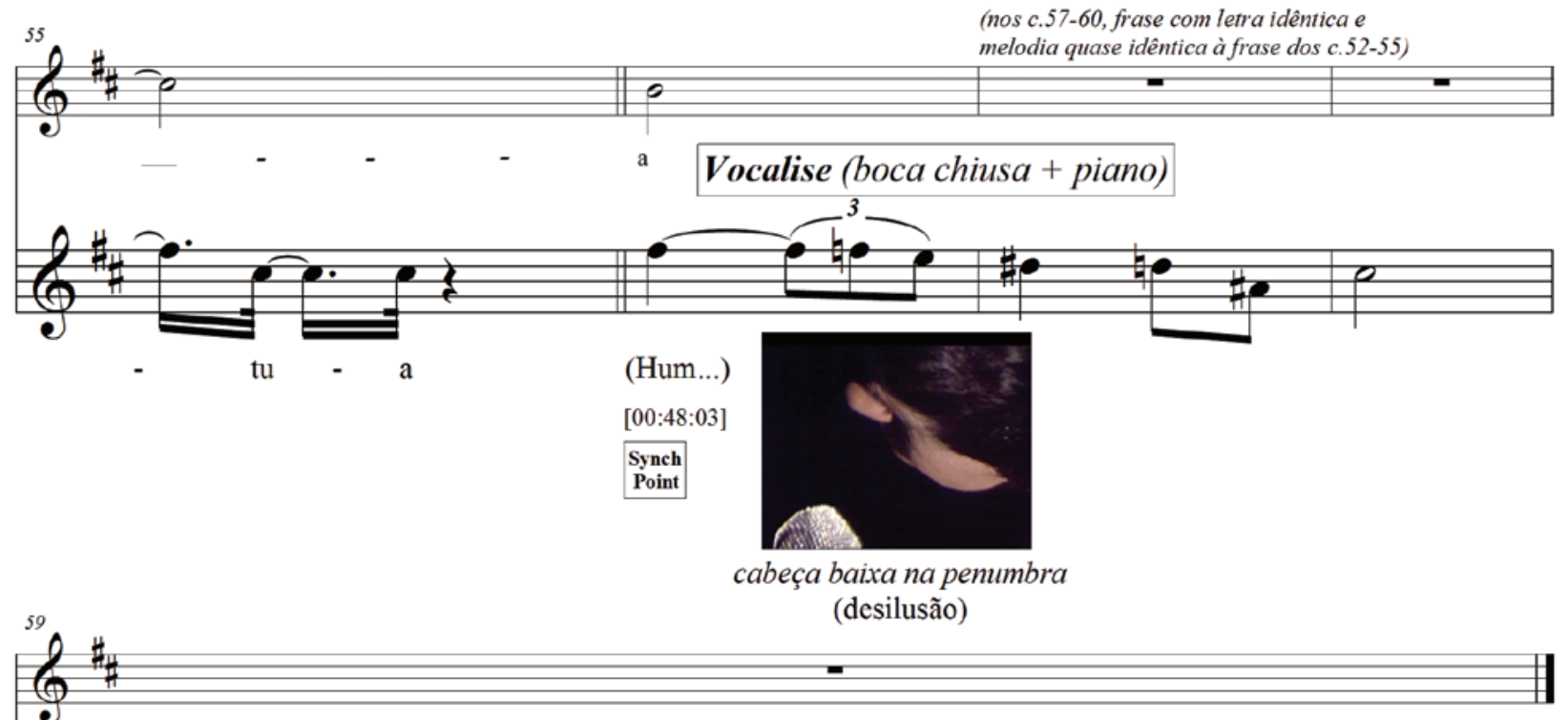

[00:48:13]

Solo de piano etc.

[00:48:36]

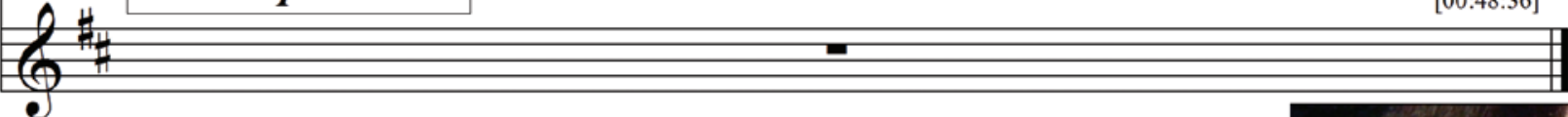

\section{Atrás da Porta}

Seção A Quando olhaste bem nos olhos meus / E o teu olhar era de adeus Juro que não acreditei / Eu te estranhei Me debrucei sobre o teu corpo / E duvidei

Seção B1 E me arrastei / E te arranhei / E me agarrei nos teus cabelos No teu peito*** / Teu pijama / Nos teus pés / Ao pé da cama

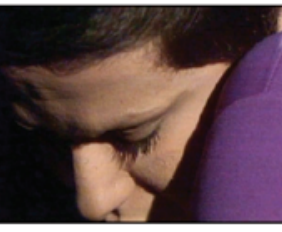

ombros encolhidos e olhos cerrados (a perda) Sem carinho, sem coberta / No tapete, atrás da porta / Reclamei baixinho

Seção B2 Dei pra maldizer o nosso lar /Pra sujar teu nome, te humilhar E me vingar**** a qualquer preço / Te adorando pelo avesso Pra mostrar qu'inda sou tua

\section{Coda Até provar***** qu'inda sou tua / (Hum...) ******}

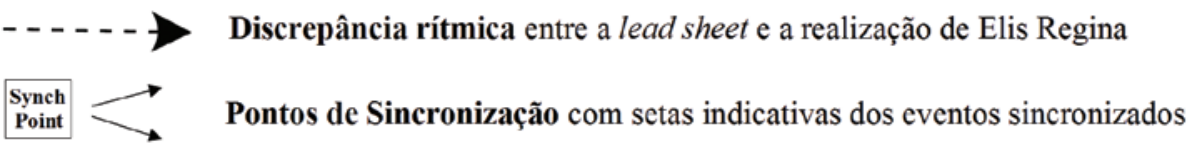

* BUARQUE, Chico; HIME, Francis. In: As 101 melhores canções do século XX: Idealização, produção e edição de Almir Chediak. v.4, $8^{a}$ ed. São Paulo: Cara Nova Editora Musical Ed., 1999. p.38-40.

** REGINA, Elis; BUARQUE, Chico; HIME, Francis. Atrás da porta. In: Na batucada da vida. De [00:44:47] a [00:48:36]. Direção de Roberto de Oliveira. Com César Camargo Mariano (piano); Hélio Delmiro (guitarra); Luizão Maia (contrabaixo); Paulinho Braga (bateria); Tom Jobim (voz); Marcelo Bôscoli, depoimento. 1973/2006 (DVD com duração de 01 hora 01 minuto e 17 segundos).

**** Alteração de Elis na letra original: "No teu peito..." ao invés de "Nos teus pelos...".

**** Alteração de Elis na letra original: "Prá me vingar..."ao invés de "Pra me entregar...".

****** Alteração de Elis na letra original: "Até provar..." ao invés de "Só pra provar...".

****** Alteração de Elis Regina no original: vocalize em boca chiusa ao invés de repetir a frase final. 